\title{
Hypoxia serves a key function in the upregulated expression of vascular adhesion protein-1 in vitro and in a rat model of hemorrhagic shock
}

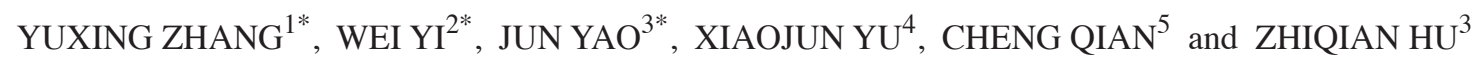 \\ ${ }^{1}$ Department of General Surgery, Navy General Hospital, Beijing 100048; ${ }^{2}$ Department of General Surgery, \\ China People's Liberation Army No. 94 Hospital, Nanchang, Jiangxi 330002; ${ }^{3}$ Department of General Surgery, \\ Shanghai Changzheng Hospital, Shanghai 200003; ${ }^{4}$ Department of Gastroenterological Surgery, \\ Zhejiang Provincial People's Hospital, Hangzhou, Zhejiang 310014; ${ }^{5}$ Department of General Surgery, \\ Huzhou Maternity \& Child Care Hospital, Huzhou, Zhejiang 313000, P.R. China
}

Received February 4, 2016; Accepted February 15, 2017

DOI: $10.3892 / \mathrm{mmr} .2017 .6727$

\begin{abstract}
Hemorrhagic shock following major trauma results in mortality, but the function of vascular adhesion protein-1 (VAP-1), implicated in intracranial hemorrhage, remains unknown. This study aimed to determine whether expression of the AOC3 gene and its encoded protein, VAP-1, is altered by hypoxia. Rat hepatic sinusoidal endothelial cells (RHSECs) and rat intestinal microvascular endothelial cells (RIMECs) were transduced with a viral vector carrying $A O C 3$, and $A O C 3$ mRNA expression levels were measured by reverse transcription-quantitative polymerase chain reaction. VAP-1 protein expression levels were measured by western blot analysis and compared between normoxic and hypoxic conditions. Following this, AOC $3 \mathrm{mRNA}$ and VAP-1 protein expression levels in hepatic and intestinal tissues were assessed in a rat model of hemorrhagic shock with or without fluid resuscitation; and serum semicarbazide-sensitive amine oxidase (SSAO) activity was measured by fluorometric assays. The effects of 2-bromoethylamine (2-BEA) on AOC3/VAP-1 levels and $24 \mathrm{~h}$ survival were investigated. AOC $3 \mathrm{mRNA}$ and VAP-1 protein levels were increased in RHSECs and RIMECs by hypoxia, and in hepatic and intestinal tissues from rats following hemorrhagic shock. Hypoxia increased serum SSAO activity in these animals. 2-BEA reduced AOC3 mRNA and VAP-1 protein levels in hepatic and intestinal tissues from
\end{abstract}

Correspondence to: Dr Zhiqian Hu, Department of General Surgery, Shanghai Changzheng Hospital, 415 Fengyang Road, Huangpu, Shanghai 200003, P.R. China

E-mail: huzhiqianmed@163.com

${ }^{*}$ Contributed equally

Key words: hypoxia, AOC3, vascular adhesion protein-1, hemorrhagic shock, rat hepatic sinusoidal endothelial cells, rat intestinal microvascular endothelial cells rats following hemorrhagic shock, and appeared to improve survival in animals not receiving resuscitation following hemorrhagic shock. In conclusion, hemorrhagic shock upregulates $A O C 3 / \mathrm{VAP}-1$ expressions, and this potentially occurs via hypoxia. Therefore, inhibition of VAP-1 may be beneficial in the setting of hemorrhagic shock. Further studies are required to confirm these findings and to establish whether VAP-1 may be a valid target for the development of novel therapies for hemorrhagic shock.

\section{Introduction}

Trauma is a leading cause of death in people aged 5-44 years (1), and $>50 \%$ of early deaths following trauma are due to major hemorrhage (2). The loss of blood during hemorrhagic shock results in hemodynamic instability, coagulopathy, reduced tissue perfusion and oxygen delivery, and therefore cellular hypoxia $(3,4)$. In turn, this results in organ failure, including the liver (5) and intestine (6). Management of hemorrhagic shock includes interventions to control the bleeding, coagulation support, administration of vasoactive drugs and resuscitation with fluids to maintain tissue oxygenation $(3,4,7)$. However, the mortality rate following major hemorrhage remains high, emphasizing the need for novel treatments. Elucidation of the cellular alterations induced by hypoxia and major hemorrhage in animal models may help identify novel therapeutic targets to minimize the detrimental effects of hemorrhagic shock and therefore improve survival.

Vascular adhesion protein-1 (VAP-1), a copper-containing amine oxidase composed of 763 amino acids, is a member of the semicarbazide-sensitive amine oxidase (SSAO) family (8). These proteins are primarily expressed in the vascular endothelial cells, adipose tissue and smooth muscle cells in humans and a variety of mammals $(9,10)$. VAP-1 is an ectoenzyme on the vascular endothelial cell surface, but is additionally expressed in the plasma as soluble VAP-1 (sVAP-1) (11). In the plasma, sVAP-1 catalyzes the transformation of aromatic and aliphatic primary amines in the blood into corresponding aldehydes, and produces $\mathrm{H}_{2} \mathrm{O}_{2}$ and 
$\mathrm{NH}_{3}$ (12-14). VAP-1 is also a homing-associated molecule, and may mediate adhesion and effusion between leukocytes and endothelial cells by antigen-antibody binding (15-20) or enzyme activity $(18,19,21,22)$. These dual functions of VAP-1 allow leukocytes to patrol throughout the body (23). Therefore, previous studies characterizing VAP-1 have focused mainly on inflammation.

It has been reported that plasma sVAP-1 concentrations are significantly increased in chronic liver disease, chronic kidney disease, septic shock and certain other diseases (24-26). In disease models of peritonitis, hepatitis, colitis, skin inflammation, stroke, sepsis, ischemia-reperfusion injury and allograft rejection, anti-VAP-1 monoclonal antibodies (mAbs) and VAP-1 enzyme inhibitors have been demonstrated to relieve inflammation by preventing leukocyte migration (17,27-32). As VAP-1 mediates leukocyte migration and adherence to vascular endothelium, it has additionally been implicated in cardiovascular and cerebrovascular diseases, including the dissemination of tumor cells (33-35) and ischemic stroke $(36,37)$. Therefore, VAP-1 may prove to be a prognostic biomarker or potential drug target (23).

However, little is known about VAP-1 regulatory mechanisms despite increasing evidence suggesting that VAP-1 is closely associated with the occurrence and development of multiple diseases. Indeed, VAP-1 expression has been well described in inflammatory reactions, and inflammation is considered a major factor that increases sVAP-1 concentration in the plasma. However, no specific pro-inflammatory factors have been identified that directly induce VAP-1 expression or stimulate signal transduction pathways that regulate VAP-1 expression $(9,38,39)$. Nonetheless, the inflammatory cascade markedly alters the local microenvironment of endothelial cells, and this may alter their gene expression to allow them to adapt to the altered environment $(40,41)$.

In previous animal experiments, it has been demonstrated that the gene for VAP-1 (AOC3) was differentially expressed in hepatic and intestinal tissues between rats surviving severe hemorrhagic shock and those that died within an hour following induction of shock (42). As hypoxia is one of the major physiological insults associated with hemorrhagic shock, this raises the possibility that cellular hypoxia may be an important factor that regulates VAP-1 expression in the liver and intestine. Therefore, the present study was designed to assess the importance of severe shock and cellular hypoxia in the regulation of VAP-1 expression in the liver and intestine. The data suggested that hypoxia causes upregulation of VAP-1 expression.

\section{Materials and methods}

Cell culture. Rat hepatic sinusoidal endothelial cells (RHSECs) and rat intestinal microvascular endothelial cells (RIMECs; Wuhan PriCells Biomedical Technology Co., Ltd., Wuhan, China) were cultured in primary endothelial cell basic culture medium (Wuhan PriCells Biomedical Technology Co., Ltd.) supplemented with $1 \%$ special additives SUP-0002 (Wuhan PriCells Biomedical Technology Co., Ltd.), 10\% fetal bovine serum (FBS; Gibco; Thermo Fisher Scientific, Inc., Waltham, MA, USA), and 1\% penicillin (Shanghai Hualan Chemical Technology Co., Ltd., Shanghai, China) and streptomycin (North China Pharmaceutical Group Corp., Shijiazhuang,
China), at $37^{\circ} \mathrm{C}$ in a humid environment containing $5 \% \mathrm{CO}_{2}$. As VAP-1/SSAO expression is progressively lost with passage of cells $(43,44)$, only cells of the first generation were used in the present study. HEK 293 cells were purchased from ATCC (Manassas, VA, USA) and cultured in ATCC complete growth medium, which included ATCC-formulated Eagle's Minimum Essential Medium (ATCC) and 10\% FBS. Cells were maintained in a humidified environment at $37.0^{\circ} \mathrm{C}$ with $5 \% \mathrm{CO}_{2}$.

Construction of adenovirus vectors and transduction of adenovirus. The adenovirus vector pAd-IRES-EGFP was constructed using the Invitrogen BP Recombination and LP Recombination systems to obtain the adenovirus vector pAd-AOC3-IRES-EGFP, which was used for overexpression of rat AOC3 (Thermo Fisher Scientific, Inc.; AOC3 GeneID: NM_031582.2). The vector did not contain the endogenous rat AOC3 promoter. The pAd-AOC3-IRES-EGFP adenovirus vector was used to transfect HEK 293 cells for virus amplification. Cells were transfected using Lipofectamine 2000 (Invitrogen; Thermo Fisher Scientific, Inc.) according to the manufacturer's protocol.

RHSECs and RIMECs were divided into three experimental groups: Control, which received no adenoviral transduction; pAd-IRES-EGFP, transduced with an empty adenovirus vector (pAd-IRES-EGFP); and pAd-AOC3-IRES-EGFP, transduced with an adenovirus vector for $A O C 3$ overexpression (pAd-AOC3-IRES-EGFP). In the two transduction groups, cells in the logarithmic growth phase were plated on 6 -well cell culture plates at a density of $5 \times 10^{4}$ cells/well and cultured in complete medium (primary endothelial cell basic culture medium, supplemented as above) for $24 \mathrm{~h}$. The medium was replaced with fresh medium and the cells were transduced (multiplicity of infection $[\mathrm{MOI}]=10$ ) with the adenovirus vector for $24 \mathrm{~h}$, and subsequently cultured under either normoxic (95\% air, $\left.5 \% \mathrm{CO}_{2}\right)$ or hypoxic $\left(95 \% \mathrm{~N}_{2}\right.$, $5 \% \mathrm{CO}_{2}$ ) conditions for $24 \mathrm{~h}$. AOC 3 mRNA expression and VAP-1 protein expression were subsequently determined using reverse transcription-quantitative polymerase chain reaction (RT-qPCR) and western blotting, respectively.

Animals and grouping. Healthy specific pathogen-free (SPF) male Sprague-Dawley rats $(n=60$; weight, 200-220 g; age, 8-9 weeks), were purchased from Sino-British Sippr/BK Lab Animal Ltd. (Shanghai, China) and housed for $>1$ week in a SPF animal room at $20-25^{\circ} \mathrm{C}$ and in a 12 -h light/dark cycle, to allow for adaptation prior to experiments. Rats were fed until they reached a desired weight (300-350 g), after which surgery was performed.

The experiment was repeated 5 times; for each experiment 12 rats were randomly divided into six groups ( $n=2$ per group), and each group therefore contained a total of 10 rats following all 5 repeats. The six groups were as follows: Sham (sham operation); hemorrhagic shock (HS; hemorrhagic shock with no resuscitation); HS/R group (hemorrhagic shock/resuscitation following hemorrhagic shock); sham+2-bromoethylamine (2-BEA; treatment with the SSAO enzyme inhibitor 2-BEA followed by sham surgery); HS+2-BEA (treatment with 2-BEA, followed by hemorrhagic shock with no resuscitation); and HS/R+2-BEA (treatment with 2-BEA, followed by hemorrhagic shock and resuscitation). 
The present study was approved by the Institutional Animal Care and Use Committee of the Second Military Medical University (SMMU; Shanghai, China) of the People's Liberation Army (protocol number 12106). The surgical procedures were conducted at the Experimental Animal Center, and other work at the Laboratory of the College of Pharmacy, SMMU (Shanghai, China).

Treatment with 2-BEA prior to surgery. Starting 4 weeks prior to surgery, rats in the sham+2-BEA, HS+2-BEA and $\mathrm{HS} / \mathrm{R}+2-\mathrm{BEA}$ groups received intraperitoneal injections of the reversible competitive SSAO enzyme inhibitor, 2-BEA (20 mg/kg daily; Sigma-Aldrich; Merck KGaA, Darmstadt, Germany) $(45,46)$. Rats in the sham, HS and HS/R groups received daily intraperitoneal injections of the same volume of deionized water. The body weight of the rats was measured daily, and the drug dosage was adjusted according to the body weight.

Rat model of hemorrhagic shock and resuscitation. Surgery was performed 4 weeks following treatment with 2-BEA or vehicle (water). Rats were fasted for $12 \mathrm{~h}$ prior to surgery, but had free access to water. The rat model of hemorrhagic shock was established using a modification of Wigger's method (42). Each rat was anesthetized by intraperitoneal injection of a $3 \%$ solution of sodium pentobarbital $(30 \mathrm{mg} / \mathrm{kg}$; Sigma-Aldrich; Merck KGaA). Rats in the HS/R group were injected with sodium pentobarbital $(20 \mathrm{mg} / \mathrm{kg})$ again prior to resuscitation, and all rats were sacrificed under anesthetic, following completion of the experimental procedure.

The left carotid artery was dissected and connected to a polygraph (MPA-2000; Shanghai Alcott Biotech Co., Ltd., Shanghai, China) to allow monitoring of blood pressure. In addition, the right femoral artery and vein were dissected and intubated, and the femoral artery was connected to a micro-injector (ALC-IP900; Shanghai Alcott Biotech Co., Ltd.) for drawing blood. The tube in the femoral vein was temporarily locked, and was available for transfusion of blood following shock. Rats in the sham group received only femoral artery and vein intubation; no blood was drawn or transfused.

Once a stable state had been reached 10 min following intubation, blood was drawn from the right femoral artery of rats in the HS group at $2 \mathrm{ml} / \mathrm{kg} / \mathrm{min}$, until the mean arterial pressure (MAP) reached $\leq 30 \mathrm{mmHg}$. Repeat bloodletting was performed when the MAP reached $\geq 40 \mathrm{mmHg}$, and multiple drawings of blood were performed to maintain the MAP at $30-40 \mathrm{mmHg}$ for $1 \mathrm{~h}$, with no infusions given. The total volume of blood withdrawn was measured and recorded. Rats in the HS/R group were treated similarly to animals in the HS group. However, once a low MAP had been maintained for $1 \mathrm{~h}$, a transfusion was given consisting of whole blood (half the original blood loss volume) together with lactated Ringer's solution (volume, 2X the original blood-loss volume; Baxter, Deerfield, MA, USA). Following this, rat status and MAP changes were observed for $1 \mathrm{~h}$.

Following completion of the above procedures, a laparotomy was performed on sterile drapes. The hepatic left lateral lobe was cut, and $3 \mathrm{ml}$ of blood was quickly drawn from the femoral artery for measurements of the partial pressures of $\mathrm{O}_{2}$ and $\mathrm{CO}_{2}$ (i-STAT 300 blood gas analyzer; Abbott
Laboratories, Chicago, IL, USA). Subsequently, the animals were sacrificed through further bleeding. Mortality was confirmed by monitoring the blood pressure and heart rate, via the left carotid artery. Specimens of the liver were taken and sliced into small sections $(\sim 0.5 \times 0.5 \mathrm{~cm})$. Specimens of the small intestine (including the mesentery) were obtained, cut along the longitudinal axis, and then cut into small sections $(\sim 1 \times 1 \mathrm{~cm})$. All specimens were rinsed three times in phosphate-buffered saline (PBS) and stored in liquid nitrogen. Serum samples were prepared by centrifugation of the blood $\left(4^{\circ} \mathrm{C}, 3,200 \mathrm{x} \mathrm{g}, 10 \mathrm{~min}\right)$, and stored in liquid nitrogen.

The experiment was repeated to determine the $24 \mathrm{~h}$ survival rate with another set of healthy SPF male Sprague-Dawley rats ( $n=120$; weight, 200-220 g; age, 8-9 weeks), purchased from Sino-British Sippr/BK Lab Animal Ltd. and housed as aforementioned. Rats were fed until they reached a desired weight (300-350 g), and were divided into the following four groups (n=30/group): HS, HS/R, HS+2-BEA, HS/R+2-BEA. Rats underwent the same surgical procedures as aforementioned, whereby the rats were aneasthetized and monitored during the intubation/shock/recovery process. When these processes were completed, rats that survived the procedure were extubated, placed into cages, and monitored up to $24 \mathrm{~h}$.

$R T$-qPCR . Cells (RHSECs or RIMECs) were seeded into 6 -well cell culture plates and were seeded at $5 \times 10^{4}$ cells/well, and transduced as aforementioned. Total RNA was isolated from the cells, using TRIzol ${ }^{\circledR}$ (Invitrogen; Thermo Fisher Scientific, Inc.). Samples of hepatic or intestinal tissue (100 mg; which had been stored in liquid nitrogen) were transferred into a clean $10 \mathrm{ml}$ glass tube containing $1 \mathrm{ml}$ TRIzol and homogenized. The above samples were transferred into $1.5 \mathrm{ml}$ tubes and centrifuged at $12,000 \mathrm{x}$ g at $4^{\circ} \mathrm{C}$ for $5 \mathrm{~min}$. RNA purity was determined by spectroscopy [ratio of optical density at $260 \mathrm{~nm}$ to that at $\left.280 \mathrm{~nm}\left(\mathrm{OD}_{260} / \mathrm{OD}_{280}\right)=1.8-2.0\right]$ and agarose gel electrophoresis (1.0\% agarose, $1 \mathrm{ng}$ total RNA/lane). Total RNA (500 ng) was reverse transcribed into cDNA using Reverse Transcriptase M-MLV. (Takara Bio, Inc., Otsu, Japan). qPCR (TP800 Thermal Cycler Dice Real Time System; Takara Bio, Inc.) was performed with $2 \mu \mathrm{l}$ cDNA, $0.4 \mu 1$ each of forward and reverse primer, and Takara SYBR Premix Ex Taq (DRR041A; Takara Bio, Inc.) in a final reaction volume of $20 \mu \mathrm{l}$. The sequence-specific primers for AOC3 and $\beta$-actin (TaKaRa Bio Inc.) were as follows: Forward, 5'-CCT AAGGCCAACCGTGAAAAGATG-3' and reverse, 5'-GTC CCGGCCAGCCAGGTCCAG-3' for AOC3; forward, 5'-GCT CCGGCGACACCACTCAG-3' and reverse, 5'-CGCCAGCAC CGAAGAAGAAAG-3' for $\beta$-actin.

The cycling conditions were: $50^{\circ} \mathrm{C}$ for $2 \mathrm{~min}$, initial denaturation at $95^{\circ} \mathrm{C}$ for $10 \mathrm{~min}$ followed by 40 cycles of denaturation at $90^{\circ} \mathrm{C}$ for $15 \mathrm{sec}$, and annealing at $60^{\circ} \mathrm{C}$ for $1 \mathrm{~min}$. Quantitation cycle $(\mathrm{Cq})$ values of the target gene AOC3 were normalized to those of $\beta$-actin, and relative mRNA expression levels were calculated using the $2^{-\Delta \Delta \mathrm{Cq}}$ method (47). The experiment was repeated three times.

Western blotting. Cells were lysed with radioimmunoprecipitation assay buffer (Invitrogen, Thermo Fisher Scientific, Inc.) and centrifuged at $18,500 \mathrm{x}$ g for $15 \mathrm{~min}$ at $4^{\circ} \mathrm{C}$. Proteins were extracted from hepatic and intestinal tissues using Tissue 
Protein Extraction Reagent (T-PER; Pierce, Rockford, IL, USA). Frozen tissue ( $100 \mathrm{mg})$ was added to a mixture of $1 \mathrm{ml}$ T-PER reagent and protease inhibitor cocktail (Abcam, Cambridge, UK), homogenized, and centrifuged at $4^{\circ} \mathrm{C}$ for $5 \mathrm{~min}$ at $10,000 \mathrm{x}$. Total protein content was determined with a Bicinchoninic Acid protein assay kit (Pierce), and equal amounts of proteins $(100 \mu \mathrm{g})$ were separated by $10 \%$ sodium dodecyl sulfate-polyacrylamide gel electrophoresis and transferred onto polyvinylidene difluoride membranes (EMD Millipore, Billerica, MA, USA). The non-specific sites on each blot were blocked with $5 \%$ milk powder diluted in Tris-buffered saline (TBS) with $0.05 \%$ Tween-20 (TBST) for $1 \mathrm{~h}$ at room temperature. Following washing with TBST, membranes were incubated overnight at $4^{\circ} \mathrm{C}$ in the presence of primary antibodies against glyceraldehyde 3-phosphate dehydrogenase (rabbit mAb; 1:1,000; \#2118; Cell Signaling Technology, Inc., Danvers, MA, USA) and VAP-1 (mouse mAb; 1:1,000; ab81718; Abcam). Blots were subsequently incubated at room temperature for $1 \mathrm{~h}$ with the appropriate horseradish peroxidase (HRP)-conjugated secondary antibody (anti-rabbit immunoglobulin (Ig)-G (\#7074; 1:3,000) or anti-mouse IgG (\#7076; 1:6000); Cell Signaling Technology, Inc.), and developed using enhanced chemiluminescence western blotting substrate (Pierce). Band intensity was quantified using TotalLab Quant v12.0 software (TotalLab Ltd., Newcastle upon Tyne, UK). Experiments were repeated twice.

Determination of serum SSAO activity. The Fluorescent SSAO Detection kit (Cell Technology, Inc., Mountain View, CA, USA) was used to determine SSAO activity in various specimens of serum, in accordance with the manufacturer's protocol. Briefly, serum samples were diluted in $1 \mathrm{X}$ reaction buffer, and a monoamine oxidase-B inhibitor was added 30 min prior to the assay, which was performed in the dark in 96-well plates. Subsequently, $100 \mu 1$ sample or positive control were loaded in each well, followed by the addition of $100 \mu \mathrm{l}$ reaction cocktail. The mixture was incubated at $37^{\circ} \mathrm{C}$ for 1-3 h, and the plates were read using a DU-730 ultraviolet fluorescence spectrophotometer (Beckman Coulter, Inc., Brea, CA, USA) with excitation at $530 \mathrm{~nm}$ and emission at $590 \mathrm{~nm}$. Serum SSAO activity was calculated according to a standard curve and expressed in $\mathrm{mU} / \mathrm{ml}$. One unit represents the amount of enzyme required to oxidize $1 \mu \mathrm{mol}$ of SSAO substrate (benzylamine) in $1 \mathrm{~min}$ at $25^{\circ} \mathrm{C}$.

Immunohistochemistry. Immunohistochemistry experiments (labeled streptavidin-biotin method) were performed using a Streptavidin-Peroxidase Immunohistochemical Detection kit (SP-9000; ZSGB-BIO, Beijing, China). In brief, formalin-fixed, paraffin-embedded sections (thickness: $4 \mu \mathrm{m}$ ) were dewaxed with fresh xylene and subjected to gradient hydration $(100 \%$ ethanol, $95 \%$ ethanol, $60 \%$ ethanol, purified water). Following elimination of endogenous peroxidase activity (incubation with $3 \% \mathrm{H}_{2} \mathrm{O}_{2}$ for $15 \mathrm{~min}$ at room temperature), microwave antigen retrieval and incubation with normal goat serum (Abcam) for $15 \mathrm{~min}$ at $37^{\circ} \mathrm{C}$. The sections were then incubated overnight at $4^{\circ} \mathrm{C}$ with a primary antibody against VAP-1 (rabbit polyclonal; 1:200; ab187202; Abcam). Following 3 washes with PBS, the specimens were incubated with a biotin-conjugated goat anti-rabbit (1:1,000; ab6720; Abcam) secondary antibody for $15 \mathrm{~min}$ at $37^{\circ} \mathrm{C}$, followed by streptavidin-peroxidase for $15 \mathrm{~min}$ at $37^{\circ} \mathrm{C}$. The slides were stained with 3,3-diaminobenzidine for $10 \mathrm{~min}$ at room temperature, and re-stained with hematoxylin. The specimens were subsequently dehydrated in a graded series of ethanol (30, 70 and 100\%), sealed with neutral resin, and observed under a light microscope (Olympus Corporation, Tokyo, Japan). A total of 10 fields were assessed (magnification, $\mathrm{x} 100$ ) in three independent experiments.

Statistical analysis. Statistical analysis was performed using SPSS software version 17.0 (SPSS, Inc., Chicago, IL, USA). All data are expressed as the mean \pm standard deviation derived from at least three independent experiments. Statistical significance was evaluated by one-way analysis of variance followed by the least significant difference post-hoc test, or the independent samples t-test. $\mathrm{P}<0.05$ was considered to indicate a statistically significant difference.

\section{Results}

Effect of hypoxia on AOC3 mRNA expression, VAP-1 protein expression, and SSAO activity in RHSECs and RIMECs. As tissue hypoxia is a major physiologic insult arising from hemorrhagic shock, in vitro experiments were performed to investigate the effects of hypoxia on the mRNA expression of $A O C 3$ and protein expression of VAP-1 in RHSECs and RIMECs. Fluorescence microscopy revealed the successful transduction of the AD-AOC3-IRES-EGFP adenovirus vector into RHSECs (Fig. 1A) and RIMECs (Fig. 1B).

RT-qPCR revealed that, for RHSECs and RIMECs cultured under normoxic conditions, AOC 3 mRNA expression was low in blank controls and cells transduced with AD-IRES-EGFP (RHSECs, Fig. 1C; RIMECs, Fig. 1D). However, RHSECs transduced with AD-AOC3-IRES-EGFP had significantly increased AOC 3 mRNA expression levels than blank controls ( 4.3-fold increase; $\mathrm{P}<0.01 ; \mathrm{n}=3)$ and cells transduced with AD-IRES-EGFP ( 4.2-fold increase; P<0.001; $n=3$; Fig. 1C). Similarly, RIMECs transduced with AD-AOC3-IRES-EGFP had significantly increased $A O C 3$ mRNA expression than blank controls $(\sim 12.5$-fold increase; $\mathrm{P}<0.01 ; \mathrm{n}=3)$ and cells transduced with AD-IRES-EGFP ( 12.5-fold increase; $\mathrm{P}<0.01 ; \mathrm{n}=3$; Fig. 1D). In RHSECs and RIMECs, hypoxia (culture for $24 \mathrm{~h}$ in $0 \% \mathrm{O}_{2}$ ) had little or no effect on blank controls and cells transduced with AD-IRES-EGFP (Fig. 1C and D). In contrast, hypoxia caused a significant upregulation of AOC3 mRNA expression in RHSECs ( 12.1-fold increase; $\mathrm{P}<0.01 ; \mathrm{n}=3)$ and RIMECs $(\sim 3.8$-fold increase; $\mathrm{P}<0.01 ; \mathrm{n}=3)$ transduced with AD-AOC3-IRES-EGFP (Fig. 1C and D, respectively).

Western blotting revealed that under normoxic conditions, VAP-1 protein expression in RHSECs and RIMECs did not differ significantly between blank controls and cells transduced with AD-IRES-EGFP (Fig. 1E and F, respectively). RHSECs transduced with AD-AOC3-IRES-EGFP had significantly increased VAP-1 protein expression compared with blank controls $(\sim 3.3$-fold increase; $\mathrm{P}<0.001 ; \mathrm{n}=3)$ and cells transduced with AD-IRES-EGFP ( 3.4-fold increase; $\mathrm{P}<0.001 ; \mathrm{n}=3$; Fig. 1E). RIMECs transduced with AD-AOC3-IRES-EGFP additionally had significantly increased VAP-1 protein expression compared with blank controls ( 2.5-fold increase; 
A

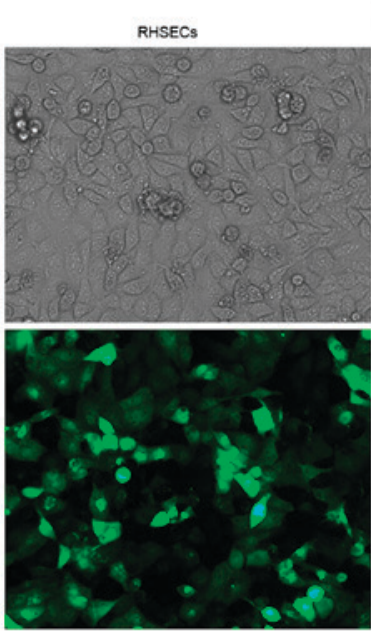

B

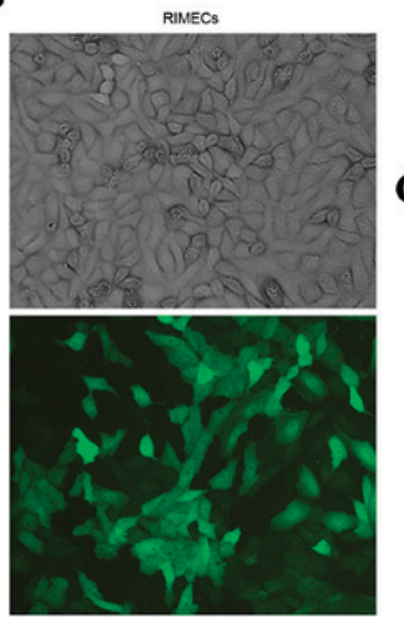

C
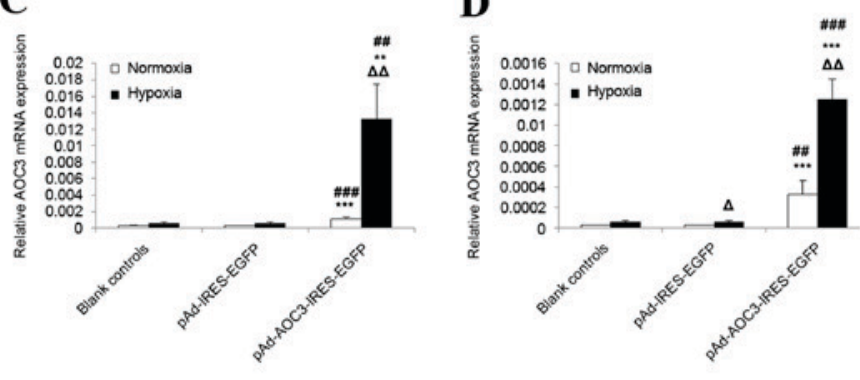
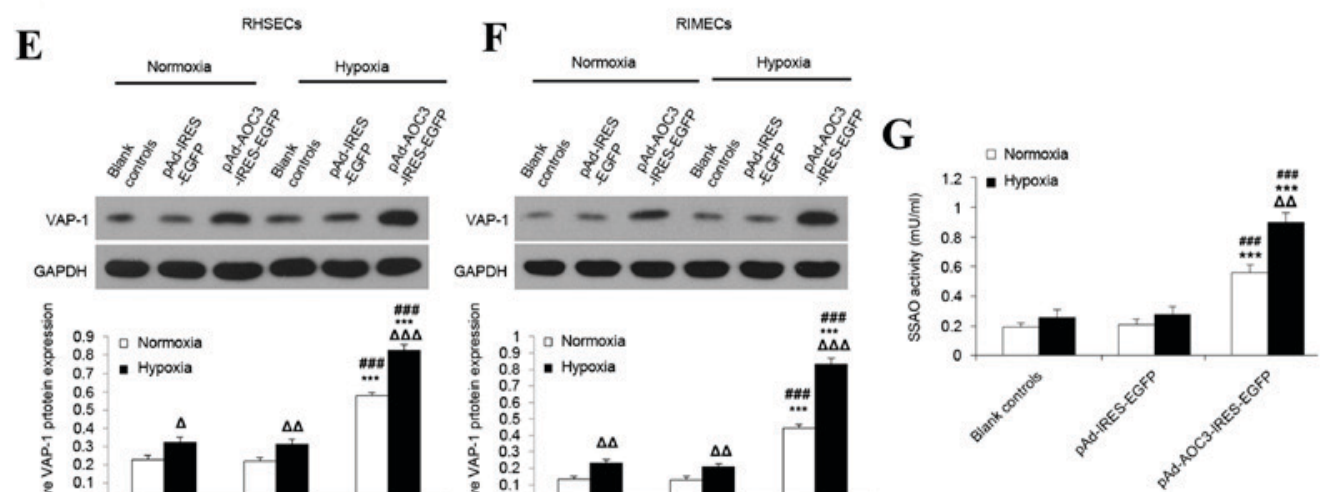

H

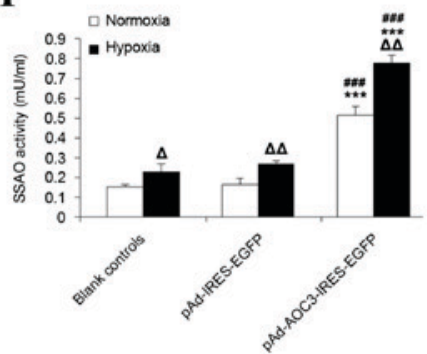

Figure 1. Effects of hypoxia on VAP-1 protein expression and AOC3 mRNA expression in RHSECs and RIMECs. RHSECs and RIMECs were transduced with pAd-AOC3-IRES-EGFP or pAd-IRES-EGFP adenovirus vectors for $72 \mathrm{~h}$; blank controls were not exposed to any adenovirus vector. Light and fluorescence microscopy images confirmed the successful transduction of (A) RHSECs and (B) RIMECs with pAd-AOC3-IRES-EGFP (magnification, x200). AOC3 mRNA expression in (C) RHSECs and (D) RIMECs under normoxic and hypoxic conditions, determined by reverse transcription-quantitative polymerase chain reaction. $\beta$-actin served as an internal control. VAP-1 protein expression in (E) RHSECs and (F) RIMECs under normoxic and hypoxic conditions, determined by western blotting. GAPDH was used as an internal control. Serum SSAO activity in (G) RHSECs and (H) RIMECs was determined using a fluorometric assay. Data are presented as the mean \pm standard deviation. ${ }^{*} \mathrm{P}<0.05,{ }^{* *} \mathrm{P}<0.01$ and ${ }^{* * *} \mathrm{P}<0.001$ vs. blank controls; ${ }^{\#} \mathrm{P}<0.05$, ${ }^{\# \#} \mathrm{P}<0.01$ and ${ }^{\# \# \#} \mathrm{P}<0.001$ vs. pAd-IRES-EGFP; ${ }^{\Delta} \mathrm{P}<0.05,{ }^{\Delta \Delta} \mathrm{P}<0.01$ and ${ }^{\Delta \Delta \Delta} \mathrm{P}<0.001$ hypoxia vs. normoxia within the same group. VAP-1, vascular adhesion protein-1; AOC3, VAP-1 gene; RHSECs, rat hepatic sinusoidal endothelial cells; RIMECs, rat intestinal microvascular endothelial cells; SSAO, semicarbazide-sensitive amine oxidase; pAd-IRES-EGFP, adenovirus control vector; pAd-AOC3-IRES-EGFP, adenovirus vector for AOC3 overexpression.

$\mathrm{P}<0.001 ; \mathrm{n}=3)$ and cells transduced with AD-IRES-EGFP ( 2.6-fold increase; $\mathrm{P}<0.001$; $\mathrm{n}=3$; Fig. 1F). In RHSECs and RIMECs, hypoxia for $24 \mathrm{~h}$ resulted in a moderate (1.4-1.7-fold) but significant enhancement of VAP-1 protein expression in blank controls $(\mathrm{P}<0.05$ and $\mathrm{P}<0.001$, respectively; $\mathrm{n}=3$; Fig. $1 \mathrm{E}$ and $F)$ and cells transduced with AD-IRES-EGFP $(\mathrm{P}<0.001$ and $\mathrm{P}<0.001 ; \mathrm{n}=3$; Fig. $1 \mathrm{E}$ and $\mathrm{F})$. Hypoxia also caused an upregulation of VAP-1 protein expression in RHSECs $(\sim 1.4$-fold increase; $\mathrm{P}<0.001 ; \mathrm{n}=3$; Fig. 1E) and RIMECs $(\sim 1.9$-fold increase; $\mathrm{P}<0.001 ; \mathrm{n}=3$; Fig. $1 \mathrm{~F})$ transduced with AD-AOC3-IRES-EGFP.

Under normoxic conditions, SSAO activity in RHSECs and RIMECs did not differ significantly between blank controls and cells transduced with AD-IRES-EGFP (Fig. 1G and $\mathrm{H}$, respectively). RHSECs transduced with
AD-AOC3-IRES-EGFP had significantly higher SSAO activity than blank controls $(\sim 2.9$-fold increase; $\mathrm{P}<0.001$; $\mathrm{n}=3)$ and cells transduced with AD-IRES-EGFP ( 2.7-fold increase; $\mathrm{P}<0.001 ; \mathrm{n}=3$; Fig. 1G). RIMECs transduced with AD-AOC3-IRES-EGFP also had significantly higher SSAO activity than blank controls $(\sim 3.4$-fold increase; $\mathrm{P}<0.001 ; \mathrm{n}=3)$ and cells transduced with AD-IRES-EGFP ( $\sim 3.2$-fold increase; $\mathrm{P}<0.001 ; \mathrm{n}=3$; Fig. $1 \mathrm{H})$. Hypoxia caused an upregulation of SSAO activity in RHSECs $(\sim 1.6$-fold increase; $\mathrm{P}=0.002 ; \mathrm{n}=3)$ and RIMECs $(\sim 1.5$-fold increase; $\mathrm{P}=0.002 ; \mathrm{n}=3)$ transduced with AD-AOC3-IRES-EGFP (Fig. $1 \mathrm{G}$ and $\mathrm{H}$, respectively).

$\mathrm{PaO}_{2}$ and $\mathrm{PaCO}_{2}$ in rats following surgically induced hemorrhagic shock or sham surgery. In view of the effects of hypoxia in RHSECs and RIMECs described above, an additional series 
of experiments was performed to determine whether changes in $A O C 3$ mRNA expression and VAP-1 protein expression were observed in vivo in a rat model of surgically induced hemorrhagic shock. Normal values for $\mathrm{PaO}_{2}$ and $\mathrm{PaCO}_{2}$ were measured in the sham group $(98 \pm 9$ and $42 \pm 4 \mathrm{mmHg}$, respectively; $n=10$; Fig. 2), whereas those in the HS group were markedly reduced $(43 \pm 6$ and $32 \pm 7 \mathrm{mmHg}$, respectively; $\mathrm{n}=10$; Fig 2), consistent with hemorrhage-induced hypoxia and a compensatory hypocapnia secondary to hypoxic stimulation of ventilation. The $\mathrm{PaO}_{2}$ and $\mathrm{PaCO}_{2}$ values in the $\mathrm{HS} / \mathrm{R}$ group were intermediate between those of the HS and sham groups ( $79 \pm 13$ and $37 \pm 5 \mathrm{mmHg}$, respectively, $\mathrm{n}=10$; Fig. 2), indicating a partial reversion of hypoxia by the administration of blood and fluids. The administration of 2-BEA had no significant effect on $\mathrm{PaO}_{2}$ and $\mathrm{PaCO}_{2}$ in all three groups ( $\mathrm{P}>0.05$; Fig. 2).

AOC3 $\mathrm{mRNA}$ expression and VAP-1 protein expression in rat hepatic and intestinal tissues following surgically-induced hemorrhagic shock or sham surgery. The expression of AOC3 mRNA in hepatic tissue was significantly increased in the HS ( 4.0-fold increase; $\mathrm{P}<0.001 \mathrm{n}=10$; Fig. $3 \mathrm{~A})$ and HS/R ( $\sim 3.2$-fold increase; $\mathrm{P}<0.001 ; \mathrm{n}=10$; Fig. $3 \mathrm{~A})$ groups compared with the sham group. Notably, mRNA expression of $A O C 3$ was significantly reduced in the HS/R group than in the HS group $(\mathrm{P}<0.05$; Fig. 3A). VAP-1 protein expression was additionally significantly increased in the HS $(\sim 2.2$-fold increase; $\mathrm{P}<0.001$; $\mathrm{n}=10$; Fig. $3 \mathrm{~B})$ and HS/R ( 1.8-fold increase; $\mathrm{P}<0.001 ; \mathrm{n}=10$; Fig. 3B) groups compared with the sham group. However, although the level of VAP-1 expression reduced in the HS/R group compared with the HS group, the difference was not statistically significant $(\mathrm{P}=0.073$; Fig. 3B).

Similar results were obtained in intestinal tissue. AOC3 mRNA expression was significantly increased in the HS ( 3.1-fold increase; $\mathrm{P}<0.001 ; \mathrm{n}=10$; Fig. $3 \mathrm{C}$ ) and HS/R $(\sim 2.3$-fold increase; $\mathrm{P}<0.001 ; \mathrm{n}=10$; Fig. $3 \mathrm{C})$ groups compared with the sham group, and significantly lower in the HS/R group than in the HS group $(\mathrm{P}<0.01$; Fig. $3 \mathrm{C})$. VAP-1 protein expression was additionally significantly increased in the HS ( 2.4-fold increase; $\mathrm{P}<0.001 ; \mathrm{n}=10$; Fig. 3D) and HS/R $(\sim 2.0$-fold increase; $\mathrm{P}<0.001 ; \mathrm{n}=10$; Fig. 3D) groups compared with the sham group, but did not differ significantly between the HS/R and HS groups ( $\mathrm{P}=0.089$; Fig. 3D).

Effect of the SSAO enzyme inhibitor, 2-BEA, on AOC3 mRNA expression and VAP-1 protein expression in rat hepatic and intestinal tissues. For hepatic and intestinal tissues, there were no significant differences in $A O C 3 \mathrm{mRNA}$ expression or VAP-1 protein expression between the sham and sham-2-BEA groups (Fig. 3). However, in hepatic tissue, AOC3 mRNA expression was reduced $\sim 1.9$-fold in the HS-2BEA group compared with the HS group $(\mathrm{P}<0.001 ; \mathrm{n}=10$; Fig. 3A), and $\sim 2$.0-fold in the HS/R-2-BEA group compared with the HS/R group $(\mathrm{P}<0.001 ; \mathrm{n}=10 ;$ Fig. $3 \mathrm{~A})$. Consistent with the changes in mRNA expression, VAP-1 protein expression in hepatic tissue was decreased $\sim 1.3$-fold in the HS-2BEA group compared with the HS group $(\mathrm{P}<0.05 ; \mathrm{n}=10$; Fig. $3 \mathrm{~B})$, and $\sim 1.5$-fold in the HS/R-2BEA group compared with the HS/R group $(\mathrm{P}<0.01$; $\mathrm{n}=10$; Fig. 3B). Similar findings were obtained in intestinal tissue. AOC3 mRNA expression in intestinal tissue was decreased $\sim 1.9$-fold in the HS-2BEA group compared with

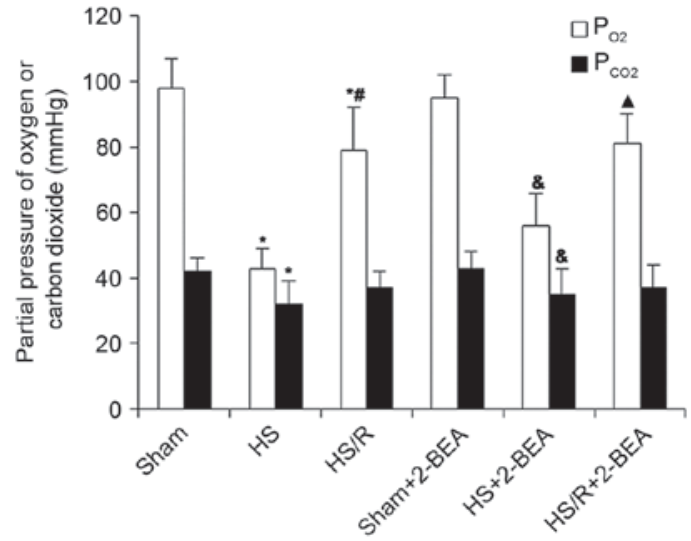

Figure 2. Arterial blood $\mathrm{PaO}_{2}$ and $\mathrm{PaCO}_{2}$ in rats. Data are presented as the mean \pm standard deviation ( $\mathrm{n}=10$ per group). ${ }^{*} \mathrm{P}<0.05$ vs. sham group; ${ }^{\#} \mathrm{P}<0.05$ vs. HS group; ${ }^{\circledR} \mathrm{P}<0.05$ vs. sham-2-BEA group; ${ }^{\boldsymbol{}} \mathrm{P}<0.05$ vs. HS-2-BEA group $\mathrm{PaO}_{2}$, partial pressure of oxygen; $\mathrm{PaCO}_{2}$, partial pressure of $\mathrm{CO}_{2}$; sham, sham operation; HS, surgically-induced hemorrhagic shock with no resuscitation; 2-BEA, 2-bromoethylamine; HS/R, surgically-induced hemorrhagic shock with resuscitation.

the HS group ( $\mathrm{P}<0.001 ; \mathrm{n}=10$; Fig. $3 \mathrm{C})$, and $\sim 1.9$-fold in the HS/R-2BEA group compared with the HS/R group $(\mathrm{P}<0.001$; $\mathrm{n}=10$; Fig. 3C). VAP-1 protein expression in intestinal tissue was reduced $~ 1.4$-fold in the HS-2BEA group compared with the HS group ( $\mathrm{P}<0.05 ; n=10$; Fig. 3D), and $\sim 1.5$-fold in the HS/R-2BEA group compared with the HS/R group ( $\mathrm{P}<0.05$; $n=10$; Fig. 3D).

Histological observations of VAP-1 protein expression. Representative immunohistologically stained sections comparing VAP-1 protein expression between the groups are presented in Fig. 4. VAP-1 was mainly distributed in the vascular endothelial cells, primarily in tissues rich in small blood vessels including the liver blood sinus and intestinal mucosal vascular endothelium. The results were similar to those obtained via western blotting.

Serum SSAO activity in rats following surgically-induced hemorrhagic shock or sham surgery, and the effects of 2-BEA. Further experiments were undertaken to establish whether alterations in $A O C 3$ mRNA expression and VAP-1 protein expression described above were reflected by alterations in serum SSAO activity in rats. Serum SSAO activity was significantly increased in the HS ( 2.7 -fold increase; $\mathrm{P}<0.001 ; \mathrm{n}=10$; Fig. 5) and HS/R ( 2.2-fold increase; $P<0.001 ; n=10$; Fig. 5) groups than in the sham group, and significantly reduced in the HS/R group than in the HS group ( $\mathrm{P}<0.01$; Fig. 5). Compared with the corresponding groups not administered with an SSAO inhibitor, 2-BEA was associated with significant reductions in serum SSAO activity in the sham-2-BEA $(\sim 1.6$-fold reduction; $\mathrm{P}<0.05 ; \mathrm{n}=10)$, HS-2-BEA ( 2.6-fold reduction; $\mathrm{P}<0.001$; $\mathrm{n}=10)$ and HS/R-2-BEA ( 2.2-fold reduction; $\mathrm{P}<0.001 ; \mathrm{n}=10)$ groups (Fig. 5).

Effect of the SSAO inhibitor, 2-BEA, on the 24 h survival rate of rats following surgically-induced hemorrhagic shock or sham surgery. The $24 \mathrm{~h}$ survival rate was $100 \%(30 / 30$ animals) in the sham and sham-2-BEA groups. In contrast, the 

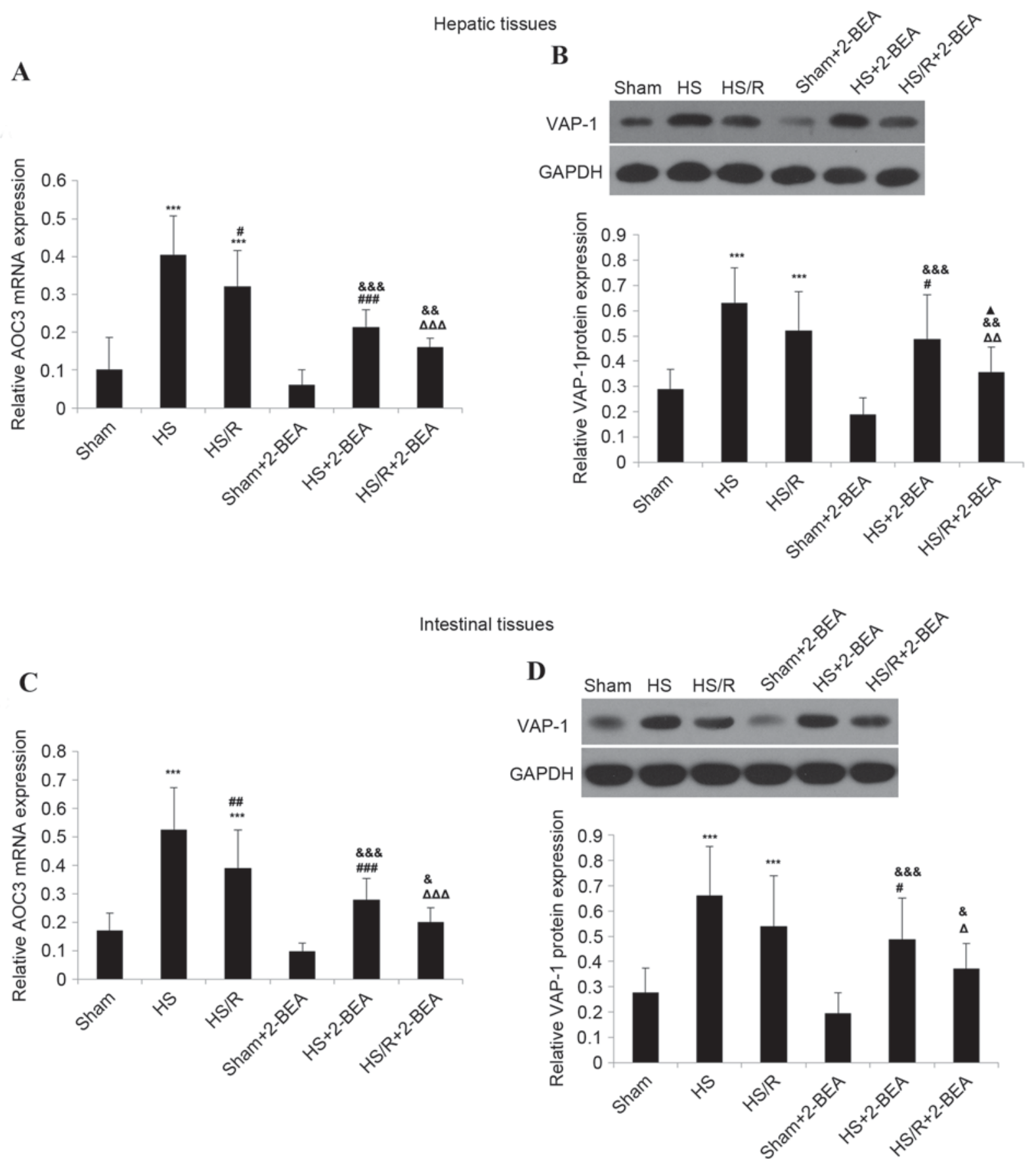

Figure 3. VAP-1 protein expression and $A O C 3 \mathrm{mRNA}$ expression in hepatic and intestinal tissues from rats of the various experimental groups, and the effects of 2-BEA. (A) AOC3 mRNA expression and (B) VAP-1 protein expression in rat hepatic tissue. (C) AOC3 mRNA expression and (D) VAP-1 protein expression in rat intestinal tissue. $\beta$-actin and GAPDH were used as internal controls for reverse transcription-quantitative polymerase chain reaction and western blotting, respectively. Data are presented as the mean \pm standard deviation ( $\mathrm{n}=10$ per group). ${ }^{* * *} \mathrm{P}<0.001$ vs. sham group; ${ }^{\#} \mathrm{P}<0.05$, ${ }^{\# *} \mathrm{P}<0.01$ and ${ }^{\# \# \#} \mathrm{P}<0.001 \mathrm{vs}$. HS group; ${ }^{\triangle} \mathrm{P}<0.05,{ }^{\Delta \Delta} \mathrm{P}<0.01$ and ${ }^{\Delta \Delta \Delta} \mathrm{P}<0.001$ vs. HS/R group; ${ }^{\&} \mathrm{P}<0.05$, \&\& $\mathrm{P}<0.01$ and ${ }^{\& \&} \& \mathrm{P}<0.001$ vs. sham-2-BEA group; ${ }^{\wedge} \mathrm{P}<0.05$ vs. HS-2-BEA group. VAP-1, vascular adhesion protein-1; AOC3, VAP-1 gene; 2-BEA, 2-bromoethylamine; sham, sham operation; HS, surgically-induced hemorrhagic shock with no resuscitation; $\mathrm{HS} / \mathrm{R}$, surgically-induced hemorrhagic shock with resuscitation.

$24 \mathrm{~h}$ survival rate was only $40 \%(12 / 30)$ in the HS group, but was $83.3 \%$ (25/30) in the HS/R group. Furthermore, the $24 \mathrm{~h}$ survival rate was $56.7 \%(17 / 30)$ in the HS-2-BEA group and $86.6 \%(26 / 30)$ in the HS/R-2-BEA group (Table I).

\section{Discussion}

The main findings of the present study were that $A O C 3 \mathrm{mRNA}$ expression and VAP-1 protein expression were upregulated by hypoxia in RHSECs and RIMECs cultured in vitro, and in hepatic and intestinal tissue obtained from an in vivo rat model of hemorrhagic shock. Furthermore, hypoxia additionally enhanced serum SSAO activity in rats subjected to experimental hemorrhagic shock. In addition, the SSAO inhibitor, 2-BEA, reduced $A O C 3$ mRNA expression and VAP-1 protein expression in hepatic and intestinal tissues from rats subjected to experimental hemorrhagic shock, and may improve $24 \mathrm{~h}$ survival in rats that did not receive resuscitation following 


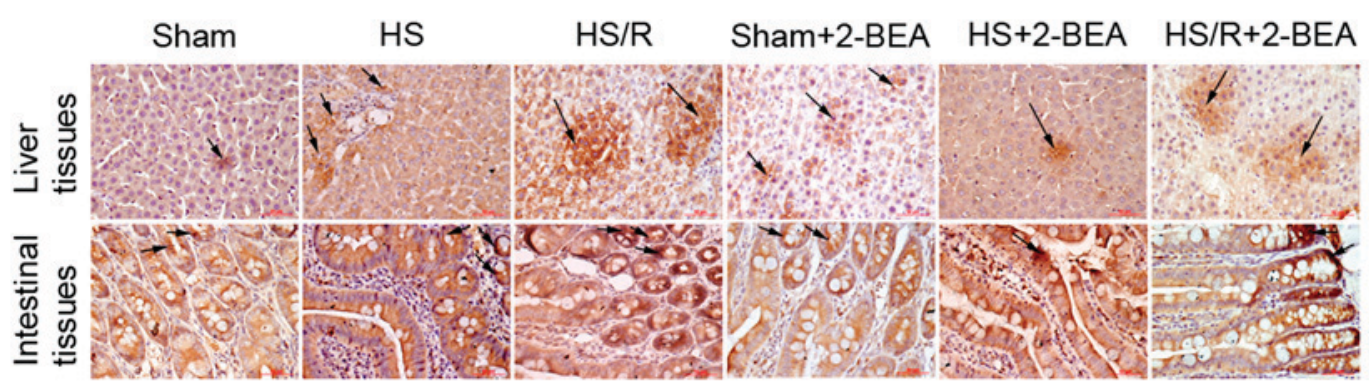

Figure 4. Representative immunohistochemistry images depicting the expression of VAP-1 protein in hepatic and intestinal tissues from rats of the various experimental groups, and the effects of 2-BEA (magnification, x400). VAP-1 was mainly distributed in the vascular endothelial cells, primarily in tissues rich in small blood vessels including the liver blood sinus and intestinal mucosal vascular endothelium. Black arrows indicate the localization of VAP-1. Brown staining represents VAP-1 and purple staining represents hematoxylin. VAP-1, vascular adhesion protein-1; 2-BEA, 2-bromoethylamine; sham, sham operation; HS, surgically-induced hemorrhagic shock with no resuscitation; HS/R, surgically-induced hemorrhagic shock with resuscitation.

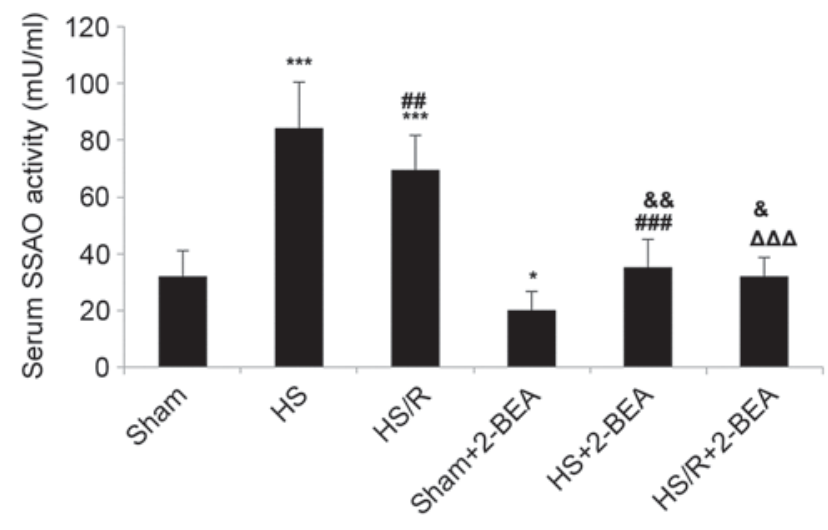

Figure 5. Serum SSAO activity in rats of the various experimental groups, and the effects of 2-BEA. Serum SSAO activity was determined using a fluorometric assay. Data are presented as the mean \pm standard deviation $(n=10$ per group). ${ }^{*} \mathrm{P}<0.05$ and ${ }^{* * * *} \mathrm{P}<0.001$ vs. sham group; ${ }^{\# \#} \mathrm{P}<0.01$ and ${ }^{\# \# \#} \mathrm{P}<0.001$ vs. HS group; ${ }^{\Delta \Delta \Delta} \mathrm{P}<0.001$ vs. HS/R group; ${ }^{\&} \mathrm{P}<0.05$ and ${ }^{\& \&} \mathrm{P}<0.01$ vs sham-2-BEA group. SSAO, semicarbazide-sensitive amine oxidase; 2-BEA, 2-bromoethylamine; sham, sham operation; HS, surgically-induced hemorrhagic shock with no resuscitation; HS/R, surgically-induced hemorrhagic shock with resuscitation.

hemorrhagic shock. Taken together, these observations suggest that hypoxia-induced upregulation of VAP-1 may be one of the mechanisms that contributes to the detrimental physiological effects of hemorrhagic shock.

VAP-1 exists in two distinct forms, as a transmembrane protein in endothelial cells and as a serum protein (9-11). For this reason, VAP-1 protein expression was studied in solid organs containing blood vessels (liver and intestine) and in the serum. The liver and small intestine (including mesentery) were chosen as parenchymal organs that are known to be susceptible to damage following hemorrhagic shock $(5,6)$. The liver, which collects venous blood from abdominal organs, contains abundant vascular endothelial tissue in the hepatic sinusoids $(11,24)$, while high endothelial venules in the mesentery of the small intestine are regarded as having high levels of VAP-1 $(9,45,46)$. In addition, hepatic and intestinal tissues in the abdominal cavity are easily collected, adding to their suitability for the in vivo study of VAP-1 expression.

The in vitro experiments were performed using RHSECs and RIMECS transduced with the $A O C 3$ gene, since the expression of $A O C 3 / \mathrm{VAP}-1$ by these cells in culture is normally very low $(18,43)$. The use of a recombinant adenovirus expressing VAP-1 permitted the study of the effects of hypoxia on VAP-1 expression. These in vitro studies revealed that culture of RHSECs or RIMECS under hypoxic conditions resulted in a significant upregulation of $A O C 3$ mRNA expression and VAP-1 protein expression. This suggested that hypoxia directly induces an increase in VAP-1 levels via enhanced transcription of the $A O C 3$ gene. These data were supported by those obtained from the in vivo rat model of hemorrhagic shock: Maintenance of a low MAP (30-40 mmHg) for $1 \mathrm{~h}$ resulted in an upregulation of $A O C 3$ mRNA expression and VAP-1 protein expression in hepatic and intestinal tissue, and this enhanced expression was inhibited by prompt resuscitation with blood and fluids. These findings indicated that regulation of VAP-1 expression occurred rapidly over a short timescale, and were consistent with a previous study, which reported that hepatic and intestinal $A O C 3$ expression differed between rats surviving hemorrhagic shock and those that died within $1 \mathrm{~h}$ (42). Notably, a previous investigation in endothelial cells expressing VAP-1 demonstrated that VAP-1 increased the susceptibility of these cells to deprivation of oxygen and glucose, and enhanced tissue damage (48). As VAP-1 also mediates leukocyte recruitment via its SSAO activity, the enhanced VAP-1 expression following hemorrhagic shock/hypoxia observed in the present study may increase the susceptibility of the liver and intestines, and potentially other organs, to damage and necrosis.

The mechanism by which hypoxia upregulates $A O C 3$ mRNA and VAP-1 protein expression remains unclear. Acute hypoxia rapidly activates endothelial cells to release inflammatory mediators and growth factors, and one hypothesis is that the regulation of VAP-1 expression by hypoxia may be mediated by hypoxia-inducible factors (HIFs). HIFs are key transcription factors that alter gene expression in hypoxic environments, and activate multiple cytokines and chemokines via regulation of signal transduction pathways $(49,50)$. However, the pathophysiologic processes underlying severe hemorrhagic shock are complicated and its consequences are reflected in multiple aspects, including alterations in the immune response, coagulation disorders, initiation of a variety of signal transduction pathways and release of numerous pro-inflammatory and anti-inflammatory cytokines. Therefore, cellular hypoxia constitutes just one step in this complex 
Table I. Effect of semicarbazide-sensitive amine oxidase enzyme inhibitor 2-BEA on $24 \mathrm{~h}$ survival rate in a rat model of hemorrhagic shock and resuscitation.

\begin{tabular}{lr} 
Group (n=30/group) & 24 h survival rate \\
\hline HS & $12(40.0)$ \\
HS/R & $25(83.3)$ \\
HS+2-BEA & $17(56.7)$ \\
HS/R+2-BEA & $26(86.6)$
\end{tabular}

Survival rate of sham group and sham +2 -BEA was $100 \%$. Sham group, sham-operation; HS group, surgically-induced hemorrhagic shock with no resuscitation; HS/R group, surgically-induced hemorrhagic shock with resuscitation; sham+2-BEA group, sham-operation, pre-treated with the serum semicarbazide-sensitive amine oxidase enzyme inhibitor 2-bromoethylamine; HS+2-BEA group, surgically-induced hemorrhagic shock with no resuscitation, pre-treated with 2-bromoethylamine; HS/R+2-BEA group, surgically-induced hemorrhagic shock with resuscitation, pre-treated with 22-bromoethylamine.

process, and the upregulation of VAP-1 expression may be due to factors other than hypoxia. Nonetheless, the in vitro experiments support the idea that hypoxia is the primary factor that causes increased expression of VAP-1.

A notable finding of the in vivo experiments was that hemorrhagic shock was associated with an increase in the activity of serum SSAO, and that this enhancement was attenuated by prompt resuscitation. This suggested that hemorrhagic shock results in the detachment of VAP-1 from the surface of endothelial cells, raising the possibility that circulating VAP-1 may be involved in severe shock. In support of these observations, deprivation of oxygen and glucose has been demonstrated to stimulate the release of sVAP-1, via a mechanism partially mediated by matrix metalloproteinase-2 (48). In addition, an increase in plasma sVAP-1/SSAO activity following intracranial hemorrhage has been reported in humans, and serum sVAP-1/SSAO activity $<2.7 \mathrm{pmol} / \mathrm{min} / \mathrm{mg}$ is an independent predictor of neurologic improvement following hemorrhagic stroke (51).

For competitive inhibitors, increasing the dose of the drug results in the enzyme being almost completely inhibited. 2-BEA is a reversible competitive enzyme inhibitor, and enzyme function is associated with the concentration of 2-BEA. The action time of 2-BEA is short and it needs regular, continuous administration in order to maintain stable blood drug concentration and effect $(52,53)$. In the pre-experiment, three doses were tested: 10,20 and $30 \mathrm{mg} / \mathrm{kg}$. There were no significant differences in SSAO activity between the $10 \mathrm{mg} / \mathrm{kg}$ and control groups. The mortality rate of rats injected with $30 \mathrm{mg} / \mathrm{kg}$ was high. Therefore, the $20 \mathrm{mg} / \mathrm{kg}$ dose was selected. As expected, the administration of the SSAO inhibitor, 2-BEA, resulted in a decrease in serum SSAO activity in rats, irrespective of whether they were subjected to hemorrhagic shock (with or without resuscitation). However, a notable finding in animals that had received surgically-induced hemorrhagic shock was that 2-BEA additionally reduced the expression of $A O C 3 \mathrm{mRNA}$ and
VAP-1 protein in intestinal and liver tissues, while no such effect of 2-BEA was observed in the sham group. This implied that, at least under the conditions of hemorrhagic shock, a degree of positive feedback exists whereby VAP-1 is able to upregulate the expression of its gene. The potential mechanisms underlying this effect remain unknown. However, previous studies have demonstrated that VAP-1 not only serves a pro-inflammatory function through its SSAO activity, but rapidly regulates the expression of inflammatory factors including E-selectin, intracellular adhesion molecule 1 (ICAM-1), vascular cell adhesion protein-1 and C-X-C motif chemokine ligand 8 , tvia activation of signaling pathways including nuclear factor- $\kappa \mathrm{B}$, phosphoinositide 3 -kinase and mitogen-activated protein kinases $(54,55)$. Nevertheless, there is a possibility that chronic treatment with 2-BEA may alter other molecular targets or molecular pathways responsible for the decreased AO3C and VAP-1 expression. Further studies are warranted to elucidate the mechanisms by which the SSAO activity of VAP-1 leads to upregulation of AOC3 mRNA and VAP-1 protein expression during hemorrhagic shock.

Another notable finding was that 2-BEA improved $24 \mathrm{~h}$ survival in rats subjected to hemorrhagic shock without resuscitation. This finding is consistent with numerous studies demonstrating a benefit of SSAO inhibition in intracranial hemorrhage/ischemia. In a rat model of subarachnoid hemorrhage, SSAO inhibition has been reported to decrease leukocyte trafficking and improve neurologic outcome (56), and prevent dysfunction of arteriolar dilation, potentially via suppression of neutrophil recruitment (57). Similarly, SSAO inhibition has been demonstrated to reduce neutrophil extravasation and infarct volume in a rat middle cerebral artery occlusion model (58). In addition, inhibitors of SSAO have been demonstrated to reduce neurobehavioral deficits and brain edema following intracerebral hemorrhage, potentially via a mechanism involving reduced neutrophil infiltration, microglia/macrophage activation, and expression of ICAM-1, monocyte chemoattractant protein-1 and tumor necrosis factor- $\alpha$ (59). Previous clinical data have revealed increased VAP-1 expression in the inflammatory response of local vasculature $(9,11,18)$. Furthermore, anti-VAP-1 mAbs and SSAO inhibitors have been demonstrated to partially restrain endovascular extravasation of lymphocytes, neutrophils, and macrophages into the peritoneum, liver, pancreas and other tissues during an inflammatory response $(28,29,60)$, and to suppress the inflammatory response in conditions including colitis, skin infection, ischemia-reperfusion injury, sepsis, pulmonary infection, arthritis and experimental allergic cerebrospinal meningitis $(19,22,30,31)$. Thus, VAP-1 is an important factor in the inflammatory cascade $(17,61)$, and its upregulation during hemorrhagic shock may contribute to the detrimental processes that result in tissue damage.

In conclusion, the present study provided evidence that VAP-1 expression is upregulated by hypoxia during acute hemorrhagic shock, and that inhibition of VAP-1 may be beneficial in the setting of hemorrhagic shock. Further studies are required to confirm these findings and to establish whether VAP-1 may be a valid target for the development of novel therapies for hemorrhagic shock. 


\section{Acknowledgements}

The present study was supported by the National Natural Science Foundation of China (grant no. 81101419).

\section{References}

1. Kauvar DS, Lefering R and Wade CE: Impact of hemorrhage on trauma outcome: An overview of epidemiology, clinical presentations, and therapeutic considerations. J Trauma 60 (6 Suppl): S3-S11, 2006.

2. Rossaint R, Cerny V, Coats TJ, Duranteau J, Fernández-Mondéjar E, Gordini G, Stahel PF, Hunt BJ, Neugebauer E and Spahn DR: Key issues in advanced bleeding care in trauma. Shock 26: 322-331, 2006.

3. Angele MK, Schneider CP and Chaudry IH: Bench-to-bedside review: Latest results in hemorrhagic shock. Crit Care 12: 218 , 2008

4. Gann DS and Drucker WR: Hemorrhagic shock. J Trauma Acute Care Surg 75: 888-895, 2013

5. Karmaniolou II, Theodoraki KA, Orfanos NF, Kostopanagiotou GG, Smyrniotis VE, Mylonas AI and Arkadopoulos NF: Resuscitation after hemorrhagic shock: The effect on the liver-a review of experimental data. J Anesth 27: 447-460, 2013.

6. Novosad VL, Richards JL, Phillips NA, King MA and Clanton TL: Regional susceptibility to stress-induced intestinal injury in the mouse. Am J Physiol Gastrointest Liver Physiol 305 G418-G426, 2013.

7. Spahn DR, Cerny V, Coats TJ, Duranteau J, Fernández-Mondéjar E, Gordini G, Stahel PF, Hunt BJ, Komadina R, Neugebauer E, et al: Management of bleeding following major trauma: A European guideline. Crit Care 11: R17, 2007.

8. Smith DJ, Salmi M, Bono P, Hellman J, Leu T and Jalkanen S: Cloning of vascular adhesion protein 1 reveals a novel multifunctional adhesion molecule. J Exp Med 188: 17-27, 1998.

9. Salmi M, Kalimo K and Jalkanen S: Induction and function of vascular adhesion protein-1 at sites of inflammation. J Exp Med 178: 2255-2260, 1993

10. Morris NJ, Ducret A, Aebersold R, Ross SA, Keller SR and Lienhard GE: Membrane amine oxidase cloning and identification as a major protein in the adipocyte plasma membrane. J Biol Chem 272: 9388-9392, 1997.

11. Kurkijarvi R, Adams DH, Leino R, Möttönen T, Jalkanen S and Salmi M: Circulating form of human vascular adhesion protein-1 (VAP-1): Increased serum levels in inflammatory liver diseases. J Immunol 161: 1549-1557, 1998.

12. Klinman JP and Mu D: Quinoenzymes in biology. Annu Rev Biochem 63: 299-344, 1994.

13. Lyles GA: Mammalian plasma and tissue-bound semicarbazide-sensitive amine oxidases: Biochemical, pharmacological and toxicological aspects. Int J Biochem Cell Biol 28: 259-274, 1996.

14. Wilmot CM, Hajdu J, McPherson MJ, Knowles PF and Phillips SE: Visualization of dioxygen bound to copper during enzyme catalysis. Science 286: 1724-1728, 1999

15. McNab G, Reeves JL, Salmi M, Hubscher S, Jalkanen S and Adams DH: Vascular adhesion protein 1 mediates binding of $\mathrm{T}$ cells to human hepatic endothelium. Gastroenterology 110: $522-528,1996$

16. Jaakkola K, Jalkanen S, Kaunismäki K, Vänttinen E, Saukko P, Alanen K, Kallajoki M, Voipio-Pulkki LM and Salmi M: Vascular adhesion protein-1, intercellular adhesion molecule-1 and P-selectin mediate leukocyte binding to ischemic heart in humans. J Am Coll Cardiol 36: 122-129, 2000.

17. Tohka S, Laukkanen M, Jalkanen S and Salmi M: Vascular adhesion protein 1 (VAP-1) functions as a molecular brake during granulocyte rolling and mediates recruitment in vivo. FASEB J 15: 373-382, 2001.

18. Lalor PF, Edwards S, McNab G, Salmi M, Jalkanen S and Adams DH: Vascular adhesion protein-1 mediates adhesion and transmigration of lymphocytes on human hepatic endothelial cells. J Immunol 169: 983-992, 2002.

19. Koskinen K, Vainio PJ, Smith DJ, Pihlavisto M, Ylä-Herttuala S, Jalkanen S and Salmi M: Granulocyte transmigration through the endothelium is regulated by the oxidase activity of vascular adhesion protein-1 (VAP-1). Blood 103: 3388-3395, 2004.
20. Aspinall AI, Curbishley SM, Lalor PF, Weston CJ, Blahova M, Liaskou E, Adams RM, Holt AP and Adams DH: CX(3)CR1 and vascular adhesion protein-1-dependent recruitment of CD16(+) monocytes across human liver sinusoidal endothelium. Hepatology 51: 2030-2039, 2010.

21. Stolen CM, Marttila-Ichihara F, Koskinen K, Yegutkin GG, Turja R, Bono P, Skurnik M, Hänninen A, Jalkanen S and Salmi M: Absence of the endothelial oxidase AOC3 leads to abnormal leukocyte traffic in vivo. Immunity 22: 105-115, 2005.

22. Marttila-Ichihara F, Smith DJ, Stolen C, Yegutkin GG, Elima K, Mercier N, Kiviranta R, Pihlavisto M, Alaranta S, Pentikäinen $\mathrm{U}$, et al: Vascular amine oxidases are needed for leukocyte extravasation into inflamed joints in vivo. Arthritis Rheum 54: 2852-2862, 2006

23. Salmi M and Jalkanen S: Homing-associated molecules CD73 and VAP-1 as targets to prevent harmful inflammations and cancer spread. FEBS Lett 585: 1543-1550, 2011.

24. Weston CJ and Adams DH: Hepatic consequences of vascular adhesion protein-1 expression. J Neural Transm (Vienna) 118: 1055-1064, 2011.

25. Lin MS, Li HY, Wei JN, Lin CH, Smith DJ, Vainio J, Shih SR, Chen YH, Lin LC, Kao HL, et al: Serum vascular adhesion protein-1 is higher in subjects with early stages of chronic kidney disease. Clin Biochem 41: 1362-1367, 2008.

26. Sallisalmi M, Tenhunen J, Yang R, Oksala N and Pettilä V: Vascular adhesion protein-1 and syndecan-1 in septic shock. Acta Anaesthesiol Scand 56: 316-322, 2012.

27. Martelius T, Salaspuro V, Salmi M, Krogerus L, Höckerstedt K, Jalkanen S and Lautenschlager I: Blockade of vascular adhesion protein-1 inhibits lymphocyte infiltration in rat liver allograft rejection. Am J Pathol 165: 1993-2001, 2004.

28. Merinen M, Irjala H, Salmi M, Jaakkola I, Hänninen A and Jalkanen S: Vascular adhesion protein-1 is involved in both acute and chronic inflammation in the mouse. Am J Pathol 166: 793-800, 2005

29. Bonder CS, Norman MU, Swain MG, Zbytnuik LD, Yamanouchi J, Santamaria P, Ajuebor M, Salmi M, Jalkanen S and Kubes P: Rules of recruitment for Th1 and Th2 lymphocytes in inflamed liver: A role for alpha-4 integrin and vascular adhesion protein-1. Immunity 23: 153-163, 2005.

30. Salter-Cid LM, Wang E, O'Rourke AM, Miller A, Gao H, Huang L, Garcia A and Linnik MD: Anti-inflammatory effects of inhibiting the amine oxidase activity of semicarbazide-sensitive amine oxidase. J Pharmacol Exp Ther 315: 553-562, 2005.

31. Xu HL, Salter-Cid L, Linnik MD, Wang EY, Paisansathan C and Pelligrino DA: Vascular adhesion protein-1 plays an important role in postischemic inflammation and neuropathology in diabetic, estrogen-treated ovariectomized female rats subjected to transient forebrain ischemia. J Pharmacol Exp Ther 317: 19-29, 2006.

32. O'Rourke AM, Wang EY, Miller A, Podar EM, Scheyhing K, Huang L, Kessler C, Gao H, Ton-Nu HT, Macdonald MT, et al: Anti-inflammatory effects of LJP 1586 [Z-3-fluoro-2-(4-methoxybenzyl)allylamine hydrochloride], an amine-based inhibitor of semicarbazide-sensitive amine oxidase activity. J Pharmacol Exp Ther 324: 867-875, 2008

33. Irjala H, Salmi M, Alanen K, Grénman R and Jalkanen S: Vascular adhesion protein 1 mediates binding of immunotherapeutic effector cells to tumor endothelium. J Immunol 166: 6937-6943, 2001

34. Marttila-Ichihara F, Auvinen K, Elima K, Jalkanen S and Salmi M: Vascular adhesion protein-1 enhances tumor growth by supporting recruitment of Gr-1+CD11b+ myeloid cells into tumors. Cancer Res 69: 7875-7883, 2009.

35. Yasuda H, Toiyama Y, Ohi M, Mohri Y, Miki C and Kusunoki M: Serum soluble vascular adhesion protein-1 is a valuable prognostic marker in gastric cancer. J Surg Oncol 103: 695-699, 2011.

36. Airas L, Lindsberg PJ, Karjalainen-Lindsberg ML, Mononen I, Kotisaari K, Smith DJ and Jalkanen S: Vascular adhesion protein-1 in human ischaemic stroke. Neuropathol Appl Neurobiol 34: 394-402, 2008.

37. Hernandez-Guillamon M, Garcia-Bonilla L, Solé M, Sosti V, Parés M, Campos M, Ortega-Aznar A, Domínguez C, Rubiera M, Ribó M, et al: Plasma VAP-1/SSAO activity predicts intracranial hemorrhages and adverse neurological outcome after tissue plasminogen activator treatment in stroke. Stroke 41: 1528-1535, 2010.

38. Arvilommi AM, Salmi M and Jalkanen S: Organ-selective regulation of vascular adhesion protein-1 expression in man. Eur J Immunol 27: 1794-1800, 1997. 
39. Martelius T, Salmi M, Wu H, Bruggeman C, Höckerstedt K, Jalkanen $\mathrm{S}$ and Lautenschlager I: Induction of vascular adhesion protein-1 during liver allograft rejection and concomitant cytomegalovirus infection in rats. Am J Pathol 157: 1229-1237, 2000.

40. Galley HF and Webster NR: The immuno-inflammatory cascade. Br J Anaesth 77: 11-16, 1996.

41. Lamb RE and Goldstein BJ: Modulating an oxidative-inflammatory cascade: Potential new treatment strategy for improving glucose metabolism, insulin resistance, and vascular function. Int J Clin Pract 62: 1087-1095, 2008.

42. Xiaojun Y, Cheng Q, Yuxing Z and Zhiqian H: Microarray analysis of differentially expressed background genes in rats following hemorrhagic shock. Mol Biol Rep 39: 2045-2053, 2012.

43. Solé $M$ and Unzeta $M$ : Vascular cell lines expressing SSAO/VAP-1: A new experimental tool to study its involvement in vascular diseases. Biol Cell 103: 543-557, 2011.

44. Sun P, Esteban G, Inokuchi T, Marco-Contelles J, Weksler BB, Romero IA, Couraud PO, Unzeta M and Solé M: Protective effect of the multitarget compound DPH-4 on human SSAO/VAP-1-expressing hCMEC/D3 cells under oxygen-glucose deprivation conditions: An in vitro experimental model of cerebral ischaemia. Br J Pharmacol 172: 5390-5402, 2015.

45. Salmi M and Jalkanen S: Different forms of human vascular adhesion protein-1 (VAP-1) in blood vessels in vivo and in cultured endothelial cells: Implications for lymphocyte-endothelial cell adhesion models. Eur J Immunol 25: 2803-2812, 1995.

46. Johansson EL, Rudin A, Wassén L and Holmgren J: Distribution of lymphocytes and adhesion molecules in human cervix and vagina. Immunology 96: 272-277, 1999

47. Livak KJ and Schmittgen TD: Analysis of relative gene expression data using real-time quantitative PCR and the 2(-Delta Delta C(T)) Method. Methods: 402-408, 2001.

48. Sun P, Solé M and Unzeta M: Involvement of SSAO/VAP-1 in oxygen-glucose deprivation-mediated damage using the endothelial hSSAO/VAP-1-expressing cells as experimental model of cerebral ischemia. Cerebrovasc Dis 37: 171-180, 2014.

49. Imtiyaz HZ and Simon MC: Hypoxia-inducible factors as essential regulators of inflammation. Curr Top Microbio Immunol 345: 105-120, 2010

50. Greer SN, Metcalf JL, Wang Y and Ohh M: The updated biology of hypoxia-inducible factor. EMBO J 31: 2448-2460, 2012

51. Hernandez-Guillamon M, Solé M, Delgado P, García-Bonilla L, Giralt D, Boada C, Penalba A, García S, Flores A, Ribó M, et al: VAP-1/SSAO plasma activity and brain expression in human hemorrhagic stroke. Cerebrovasc Dis 33: 55-63, 2012.
52. Kinemuchi H, Kobayashi N, Takahashi K, Takayanagi K, Arai Y, Tadano T, Kisara $\mathrm{K}$ and Oreland L: Inhibition of tissue-bound semicarbazide-sensitive amine oxidase by two haloamines, 2-bromoethylamine and 3-bromopropylamine. Arch Biochem Biophys 385: 154-161, 2001.

53. Kobayashi N, Takahashi K, Takayanagi K, Takahashi K, Masuko S, Tadano T, Kisara K and Kinemuchi H: Molecular characteristics of tissue-bound semicarbazide-sensitive amine oxidase (SSAO) in guinea pig tissues. Life Sci 70: 1519-1531, 2002.

54. Lalor PF, Sun PJ, Weston CJ, Martin-Santos A, Wakelam MJ and Adams DH: Activation of vascular adhesion protein-1 on liver endothelium results in an NF-kappaB-dependent increase in lymphocyte adhesion. Hepatology 45: 465-474, 2007.

55. Lalor PF, Tuncer C, Weston C, Martin-Santos A, Smith DJ and Adams DH: Vascular adhesion protein-1 as a potential therapeutic target in liver disease. Ann N Y Acad Sci 1110: 485-496, 2007.

56. Xu HL, Garcia M, Testai F, Vetri F, Barabanova A, Pelligrino DA and Paisansathan C: Pharmacologic blockade of vascular adhesion protein-1 lessens neurologic dysfunction in rats subjected to subarachnoid hemorrhage. Brain Res 1586: 83-89, 2014.

57. Xu H, Testai FD, Valyi-Nagy T, N Pavuluri M, Zhai F, Nanegrungsunk D, Paisansathan $\mathrm{C}$ and Pelligrino DA: VAP-1 blockade prevents subarachnoid hemorrhage-associated cerebrovascular dilating dysfunction via repression of a neutrophil recruitment-related mechanism. Brain Res 1603: 141-149, 2015.

58. Watcharotayangul J, Mao L, Xu H, Vetri F, Baughman VL, Paisansathan C and Pelligrino DA: Post-ischemic vascular adhesion protein-1 inhibition provides neuroprotection in a rat temporary middle cerebral artery occlusion model. J Neurochem 123 (Suppl 2): S116-S124, 2012.

59. Ma Q, Manaenko A, Khatibi NH, Chen W, Zhang JH and Tang J: Vascular adhesion protein-1 inhibition provides antiinflammatory protection after an intracerebral hemorrhagic stroke in mice. J Cereb Blood Flow Metab 31: 881-893, 2011.

60. O'Rourke AM, Wang EY, Salter-Cid L, Huang L, Miller A, Podar E, Gao HF, Jones DS and Linnik MD: Benefit of inhibiting SSAO in relapsing experimental autoimmune encephalomyelitis. J Neural Transm (Vienna) 114: 845-849, 2007.

61. Jalkanen S and Salmi M: VAP-1 and CD73, endothelial cell surface enzymes in leukocyte extravasation. Arterioscler Thromb Vasc Biol 28: 18-26, 2008. 